\title{
Exploration on Bilingual Modified PBL Teaching Mode in Virtual Medical Instrumentation Design
}

\author{
Lv Dan, Liu Yang, Lv Jie and Si Boyu \\ School of Medical Instrumentation in Shanghai University of Medicine \& Health Sciences \\ Shanghai, 201318 \\ E-mail: lvd@sumhs.edu.cn
}

\begin{abstract}
This paper mainly introduces the effective application of modified small case PBL (Problem-based learning) teaching mode in the bilingual teaching of Virtual Medical Instrumentation Design for clinic engineering technology specialty, and expounds the specific implementation scheme of course teaching and the organization of the teaching contents, and explores the direction of course characteristic construction. Finally, it is concluded that modified PBL teaching mode has more actual operability than traditional PBL teaching mode, and the teaching effect thereof is more ideal.
\end{abstract}

Keywords-Clinic engineering technology; Virtual medical instrumentation; Bilingual teaching; PBL

\section{INTRODUCTION}

Clinic engineering technology specialty is the only undergraduate specialty that obtains the approval of the Ministry of Education, and is aimed to cultivate biomedical engineering combined composite high-qualified clinic engineering technology applied talents. The specialty takes clinic medical instrumentation as the main carrier, and focuses on helping students to relatively system-atically master the wide biomedical engineering basic theoretical knowledge and professional practical skills in the field of international clinic engineering technology.

As one characteristic specialty course of clinic engineering technology specialty, Virtual Medical Instrumentation Design has distinct characteristics of "multi-discipline+ multi-type+ internationalization", and is also a bridge that realizes the seamless connection between students' basic theoretical knowledge and clinic engineering practice. This paper mainly introduces the valid application of modified small case PBL (Problem-based learning) teaching mode in the bilingual teaching of Virtual Medical Instrumentation Design and elaborates the specific implementation scheme of course teaching, and also conducts exploration on the course characteristic construction direction.

\section{BILINGUAL TEACHING ThOUGHT}

In the global medical instrumentation market, international medical instrumentation enterprises have obvious characteristics, such as high market share proportion, fast technical level up-grading and distinct international characteristics, which will put forward unique connotation demand for the education and teaching of clinic engineering technology specialty courses, and it is imperative to broaden knowledge caliber and adopt the international teaching mode under multi-disciplinary perspective. However, as one of the valid means for cultivating high-qualified and composite talents, bilingual teaching is also currently one of the key points and difficult problems for the higher education teaching reform of our country. Bilingual teaching has reflected the joint demand of the current social informatization and economic globalization, and is also the necessary trend for the education reform and development of colleges in our country [1].

Virtual medical instrumentation is a medical instrumentation designed on the basis of the software and hardware sources of general computers. Users can use the strong software processing function of computer to control the instrument, and organically integrate the software resources of computer and the hardware of instruments, validly combine the powerful calculation processing capacity and instrument hardware measurement and control capacity of computer, truly realize the design concept of "instrument function user customization", and then largely improve the flexibility of medical instrumentation, and largely shorten the instrument development period, and largely decrease the development cost of instrument. In course design, Virtual Medical Instrumentation Design for clinic engineering technology specialty always adheres to the basic orientation of comprehensive application capacity requirements for international clinic medical instrumentation, absorbs the advanced culture of famous medical instrumentation production, maintenance, marketing and other enterprises at home and abroad, and realizes the integration of skill cultivation and language application capacity cultivation for clinic engineering technology specialty in bilingual teaching. Meanwhile, in combination with the new development of medical instrumentation industry in our country, help student build the basic bridge for using English to conduct the professional knowledge learning of medical instrumentation and 
smooth communication. Through learning the course, students can possess the actual application capacity of professional technology skills, and reinforce their comprehensive quality and employment capacity. As a characteristic professional course, under bilingual environment, Virtual Medical Instrumentation Design is a main course for reinforcing students' academic English communication quality and improving students' international learning capacity, and it is aimed to help students fast and comprehensively master the overall design concept of virtual medical instrumentation, understand the development dynamics of medical instrumentation industry, get familiar with the typical product principal and clinic use of medical instrumentation, interpret the international development trend of medical instrumentation, etc., and then reinforce students' international communication awareness, improve their capacity for obtaining, mastering and validly using professional academic English, and lay a solid foundation for the lifelong learning and international academic communication of students.

\section{Modified Small Case PBL Teaching Mode}

\section{A. PBL teaching mode}

PBL teaching mode is a kind of teaching mode that takes problems as the center, the students as the subject and the problem-solving as the driving force [2-4]. PBL teaching mode can set teaching in the "problem" context with actual meaning, and then under the guidance of teachers, students can solve "problems" through combing the existing knowledge, and meanwhile, learn the knowledge implied in "problems", cultivate the capacity of autonomous learning, and solving problems. The essence of PBL teaching mode is to arouse students' enthusiasm and initiative through the guidance function of "problems" in study [5].

However, for the teaching practice of clinic engineering technology specialty, traditional simple PBL teaching mode is not the best choice. Traditional PBL refers to setting relatively complicated and big learning-situated context cases for students to solve. Before solving the case, students need to spend lots of time studying or searching data, discussing and analyzing problems, and then solving the problem [6-7]. However, clinic engineering technology specialty has natural characteristics, such as multi-disciplinary professional knowledge points, complicated teaching contents, and close combination with practice; under such prediction, if students are allowed to master complicated and scattered professional knowledge points on their own under the background of separating from clinic environment, the teaching effect is not ideal, so it is urgent to adopt modified PBL teaching mode to improve the teaching effect.

\section{B. Exploration on modified small case PBL teaching mode}

Modified small case PBL teaching mode practice still adheres to regarding students as the subject to carry out problem-oriented learning; meanwhile, being supplemented by CBL (Case-based learning) case teaching method, it can realize diversified teaching methods, and better stimulate students' subjective initiative, and largely improve students' learning efficiency, the solid degree for mastering knowledge and the problem-solving capacity.

In the bilingual teaching of Virtual Medical Instrumentation Design, it will further combine the characteristics of the course and the actual conditions of course setup, optimize PBL teaching mode into small case PBL teaching mode that is more suitable for professional knowledge demand, with high pertinence, and it is mainly reflected in the setup mode and setup rules of problems as well as the guidance mode of teachers. Modified small case PBL teaching mode is applied in the bilingual teaching of Virtual Medical Instrumentation Design, to practically improve the learning capacity of students as well as the capacity to solve the actual application of professional academic English.

Modified small case PBL teaching mode can optimize traditional PBL teaching problems into several "small problems", and use several "small problems" to comprehensively cover the teaching knowledge points, which can better meet the teaching demand of clinic engineering technology specialty and can facilitate students to comprehensively and systematically study and master professional theoretical knowledge and practical application. The "small problems" here mainly visualize problems, which can facilitate fast understanding, rather than decreasing the difficulty of problems, and in the teaching practice, students can fast find out the cutting point for solving problems, so modified PBL teaching mode has more actual operability than traditional PBL teaching mode, and the teaching effect is also more ideal. The key knowledge points of each teaching module unit are contained in several small case topics, and each small case topics cover one or several theoretical knowledge and academic English communication knowledge points related to Virtual Medical Instrumentation Design, such as the instrument configuration of clinic hospital typical department, the basic principle of X-ray machine highpressure generator, and the ECG machine scale operation rules. Small case topics should be close to the actual application context.

\section{TEACHING CONTENTS ORGANIZATION AND ARRANGEMENTS}

This paper takes Virtual ECG Machine (Electrocardiograph) teaching module as the example, and specifically introduces the specific realization of modified small case PBL teaching method in the course teaching.

Traditional ECG recording method mainly relies on ECG machine for completion, and the signal collection, processing and display are mainly completed through the hardware circuit, which has a relatively high requirement for production technology, with expensive equipment price, and inconvenient maintenance and upgrading. But along with the increasingly developed virtual instrument technology, there has already had good technical support for modified traditional ECG recording equipment.

As typical electrophysiological instrument, ECG machine has already had about 100 years of history in clinic application, and is currently one of the medical instrumentation with the highest popularization rate in basic medical units. ECG 
machine, ECG, cardiac electrical activity, cardiac physiological structure and other basic concepts have constituted the natural knowledge vein of ECG machine teaching module, and traditional teaching mode basically follows such knowledge vein, and respectively teaches students relevant knowledge points step by step; the teaching contents can always be restricted in the principle and application of ECG machine, neglecting the vertical linkage excavation of ECG machine and other electrophysiological instrument; besides, the teaching contents have weak systematicness, and are mostly stored with the scattered Chinese data in the relevant field, so it is very difficult to stimulate students' subjective initiative, and cannot give full considerations to the cultivation of students' internationalization learning capacity, and this has largely decreased the course teaching effect and cannot meet the requirements for cultivating comprehensive talents.

After adopting modified small case PBL teaching method, ECG signal in MIT-BIH Arrhythmia database is regarded as the system entrance, and the typical product Cardiofax ECG9620 ECG machine produced by famous NIHON KONDEN Company in ECG machine manufacturing field as the blueprint, to guide students to start from the design of bilingual panel for the machine (as shown in Figure 1), evolve 10 big knowledge points of virtual ECG machine design teaching module into 36 bilingual small cases that are easily understood, with clear objective (as shown in Figure 2). Students can build learning groups as per their own specialties and interests, and then under the guidance of teachers, actively conduct in-depth analysis, discuss about the actual "small problems", and attempt to solve each small case through using the prerequisite course knowledge and professional comprehensive application capacity under the cooperation of the group, after that, teachers will provide targeted analysis and explanation, so that students can have a deeper understanding about the course teaching contents, learn about more theoretical knowledge and practical skills, timely correct the errors and omissions in the autonomous learning and studying process of students, and then let students learn about the professional knowledge research method within a short time, of which such method generally requires long-term theoretical class hours and practical operation accumulation, and this can facilitate students to comprehensively and fast improve their professional theoretical knowledge and clinic application skills.

After students have mastered all knowledge points of the module, teachers will guide students to simulate the working procedures of ECG machine on LabVIEW platform of the virtual instrument as per the designed machine panel. After that, on the Multisim circuit design simulation platform, conduct circuit design specific to the basic functions of virtual ECG machine through circuit design simulation; finally, simulate different effects of circuit design on virtual ECG machine, thus, it can realize: through virtual simulation method, complete the functional design of ECG machine, and then provide basis for the true hardware design and improve efficiency.

\section{Virtual ECG Viewer}

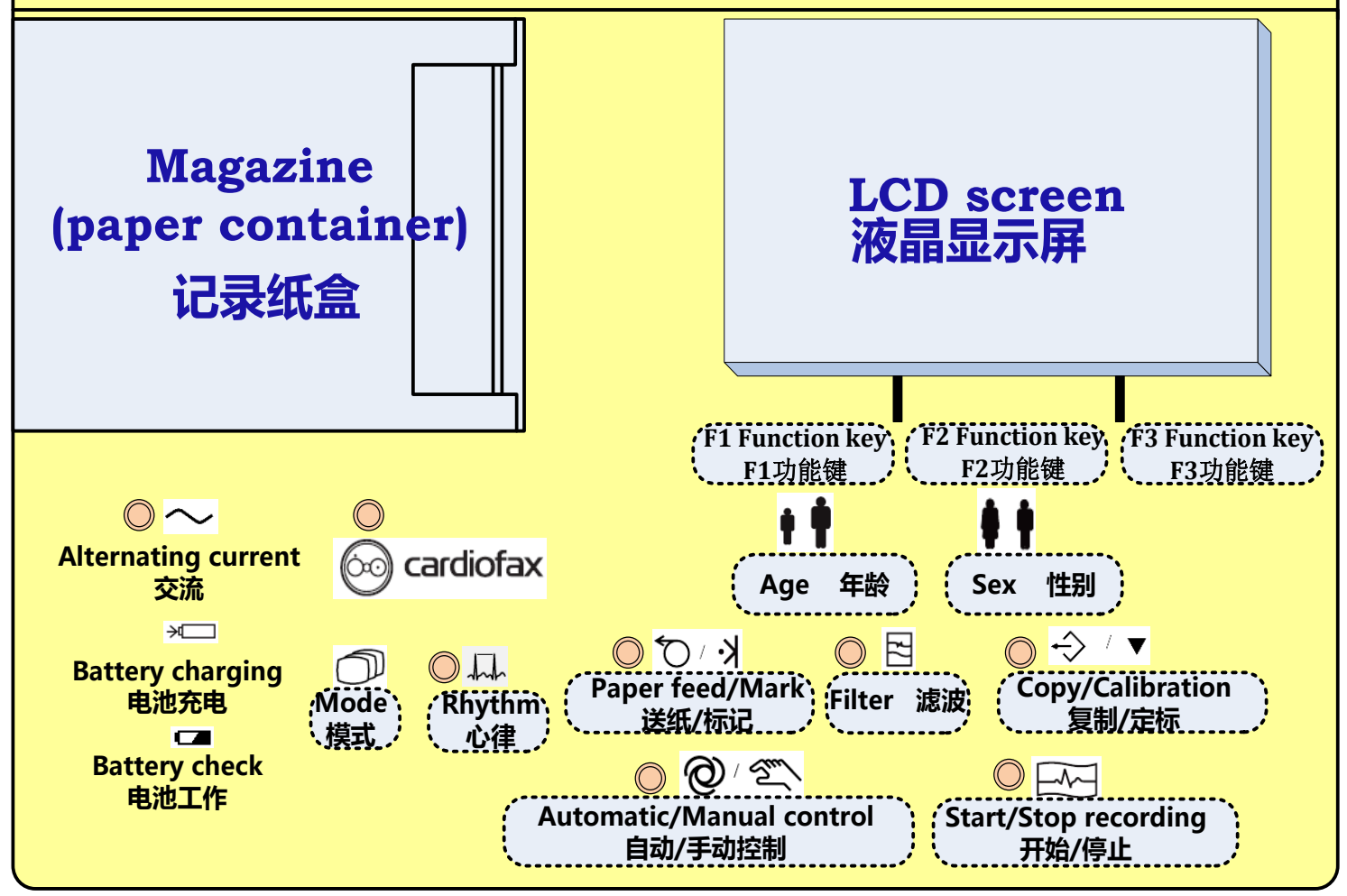

Fig. 1. Schematic Diagram about the Virtual ECG Machine Bilingual Panel Design 
TABLE I.

Virtual ECG Machine Design Module Bilingual CaSe Library

\begin{tabular}{|c|c|c|c|}
\hline \multicolumn{2}{|r|}{ Study Task } & \multirow{2}{*}{\multicolumn{2}{|c|}{ Case Library }} \\
\hline Teaching Module & Knowledge Point & & \\
\hline \multirow{3}{*}{$\begin{array}{l}\text { Virtual ECG } \\
\text { Machine design } \\
\text { and ECG signal } \\
\text { detection } \\
\text { technology analog } \\
\text { simulation }\end{array}$} & \multirow{3}{*}{$\begin{array}{ll}\text { 1. } & \text { Circulatory System } \\
\text { 2. } & \text { The heart } \\
\text { 3. } & \text { Bioelectricity } \\
\text { 4. } & \text { Electroconduction system } \\
& \text { of the heart } \\
\text { 5. } & \text { ECG signal } \\
\text { 6. } & \text { ECG lead } \\
\text { 7. } & \text { ECG amplifier } \\
\text { 8. } & \text { ECG/EEG/EOG/EMG } \\
\text { 9. } & \text { Heart rhythm } \\
\text { 10. } & \text { Heart problems }\end{array}$} & $\begin{array}{l}\text { (Power } \\
\text { Supply) }\end{array}$ & $\begin{array}{l}\text { 1. When to apply AC supply? } \\
\text { 2. When to apply DC supply? } \\
\text { 3. When to apply AC \& DC supply? } \\
\text { 4. How to switch AC supply to DC supply? } \\
\text { 5. How to switch DC supply to AC supply? } \\
\text { 6. How many kinds of battery charging states? } \\
\text { 7. When to enter battery check? } \\
\text { 8. How many switches at least are there to control the } \\
\text { power? } \\
\text { 9. How does ECG machine get its DC supply? } \\
\text { 10. How does ECG machine get its AC supply? }\end{array}$ \\
\hline & & $\begin{array}{c}\text { (Signal } \\
\text { Processing) }\end{array}$ & $\begin{array}{l}\text { 1. What is heart rhythm? } \\
\text { 2. How to get heart rhythm? } \\
\text { 3. How many mathematic ways can you get HR? } \\
\text { 4. Are there any devices to get HR besides ECG } \\
\text { machine? } \\
\text { 5. How to get ECG waveforms? } \\
\text { 6. What is lead II? } \\
\text { 7. How to describe different waves in lead II? } \\
\text { 8. How do electrodes get ECG signals? } \\
\text { 9. How many electrodes are there in ECG machine? } \\
\text { 10. How many electrodes are there in EEG machine? } \\
\text { 11. How many electrodes are there in EOG machine? } \\
\text { 12. How many electrodes are there in EMG machine? } \\
\text { 13. What is ECG lead system? } \\
\text { 14. How many kinds of leads are there? } \\
\text { 15. How to amplify the ECG signal? } \\
\text { 16. How to record the ECG waveforms? } \\
\text { 17. What is filtering? } \\
\text { 18. What is power frequency filtering? } \\
\text { 19. What is muscle filtering? } \\
\text { 20. What about paper moving speed? }\end{array}$ \\
\hline & & (Control) & $\begin{array}{l}\text { 1. What is calibration? } \\
\text { 2. How to fulfill calibration? } \\
\text { 3. How to control paper moving speed? } \\
\text { 4. What is automatic recording? } \\
\text { 5. What is manual recording? } \\
\text { 6. Can you draw the calibration waveform? }\end{array}$ \\
\hline
\end{tabular}

\section{CONCLUSION}

The practice of modified small case PBL teaching mode in the bilingual teaching of Virtual Medical Instrumentation Design course can indicate that, the small cases that are finally composed through containing the knowledge points of teaching module unit into several small case topics refer to a complete teaching system composed of the basic principle of medical instrument, typical virtual medical instrumentation design principle, clinic application practice and other organic links. It can help students master professional knowledge research method within a short time, of which the professional knowledge research method requires long-term theoretical class hours and practical operation accumulation, and it can be good for students to comprehensively and fast improve their professional theoretical knowledge and clinic application skills. In the full process of principle analysis and engineering design, it is requested to focus on problems, regard students as the subject, and use problem-solving as the driving force for teaching. Set teaching in the "problem" situation with actual meaning, and then under the guidance of teachers, students can combine the existing knowledge, to solve "problems"; meanwhile, learn the knowledge implied in "problems", cultivate their autonomous learning capacity, practice the capacity to solve problems. Practice has proved that, this complies with the objective trend for the development of modernized medical instrument technology, and can realize teaching benefits teachers as well as students, and meet the teaching practice requested for the development era of modernized clinic engineering technology. 


\section{REFERENCES}

[1] Zhang Tongli, Discussion about Reinforcing Bilingual Teaching in Colleges, China Higher Education Research, 2007 (5): 90-92.

[2] Liu Haijing, Liu Xiaolan, Ba Zaihua, and Wang Lizan, Primary Investigation about PBL Teaching Mode, Modern Medicine \& Health, 2007, 23(17): 2676-2677.

[3] Gao Xue, Advantages and Disadvantages of Problem-based Learning (PBL) in Medical Edu-cation, Basic Medical Sciences and Clinics, 2014, 34 (1): 142-144.

[4] Zhou Qing, Zhou Feng, Wu Caixia, Chen Xiaoqing and Yuan Fang, Research about the Ap-plication of PBL in Clinic Teaching, Chinese Journal of Medical Education Research, 2012, 11 (6): 591-594.

[5] Zhang Donghua, Gao Yue, Bo Hong and Dong Jingzhu, Application of Teaching Method in the Clinic Education of Our Country and the Existing Problems, China Higher Medical Education, 2012 (1): 99-100.

[6] MJ Newman, Problem Based Learning: An Introduction and Overview of the Key Features of the Approach, Journal of Veterinary Medical Education, 2005, 32 (1): 12.

[7] HG Schmidt, Problem-based learning: An introduction, Instructional Science, 1994, 22 (4): 247-250. 